\title{
Resveratrol protects SH-SY5Y neuroblastoma cells from apoptosis induced by dopamine
}

\author{
Mi Kyung Lee', Soon Ja Kang ${ }^{2}$, \\ Mortimer Poncz ${ }^{3}$, Ki-Joon Song ${ }^{4}$ \\ and Kwang Sook Park ${ }^{4,5}$ \\ ${ }^{1}$ Department of Genetics, College of Life Science \\ ${ }^{2}$ Department of Science Education \\ College of Education \\ Ewha Womans University \\ Seoul 120-750, Korea \\ ${ }^{3}$ Division of Hematology, Children's Hospital of Philadelphia \\ PA 19104, USA \\ ${ }^{4}$ Department of Microbiology and \\ Bank for Pathogenic Viruses \\ Division of Brain Korea 21 Program for Biomedical Science \\ College of Medicine, Korea University \\ Seoul 136-705, Korea \\ ${ }^{5}$ Corresponding author: Tel: 82-2-920-6164; \\ Fax: 82-2-923-3645; E-mail: parkbcmb@korea.ac.kr
}

Accepted 11 April 2007

Abbreviations: DA, dopamine; MMP, mitochondrial membrane potential; $\mathrm{PI}$, propidium iodide; PS, phosphatidyl serine

\begin{abstract}
Dopamine (DA) is an oxidant that may contribute to the degeneration of dopaminergic neurons. The present study demonstrates that DA-induced cytotoxicity in human-derived neurotypic cells, SH-SY5Y, is prevented by resveratrol, one of the major antioxidative constituents found in the skin of grapes. SH-SY5Y cells, a neuroblastoma cell line, treated with DA at 300 and $500 \mu \mathrm{M}$ for $24 \mathrm{~h}$ underwent apoptotic death as determined by characteristic morphological features, including nuclear conden sation, and loss of mitochondrial membrane poten tial (MMP). Flow cytometric analysis using Annexin V showed that DA can induce significant and severe apoptosis. Exposure to resveratrol $(5 \mu \mathrm{M})$ for $1 \mathrm{~h}$ prior to the DA treatment attenuated DA-induced cytotoxicity, and rescued the loss of MMP. To investigate the apoptotic signaling pathways relevant to the restoration of DA-induced apoptosis by resveratrol, we carried out quantitative analysis of Bcl-2, cas pase-3, and cleaved poly ADP-ribose polymerase (PARP) by immunoblot analysis. Resveratrol pre treatment led to a decrease in cleavage of PARP, an
\end{abstract}

increase in the $\mathrm{Bcl}-2$ protein, and activation of cas pase-3. These results suggest that DA may be a potential oxidant of neuronal cells at biologically relevant concentrations. Resveratrol may protect SH-SY5Y cells against this cytotoxicity, reducing intracellular oxidative stress through canonical signal pathways of apoptosis and may be of biological importance in the prevention of a dopaminergic neurodegenerative disorder such as Parkin son disease.

Keywords: antioxidant; apoptosis; dopamine; neuroblastoma; neurodegenerative diseases; resveratrol

\section{Introduction}

Parkinson's disease (PD) is a common neurodegenerative disease, characterized by a selective loss of dopaminergic neurons in the substantia nigra. Many factors are speculated to operate in the mechanism of cell death of nigrostriatal dopaminergic neurons in PD, including oxidative stress and cytotoxicity of reactive oxygen species (ROS), disturbances of intracellular calcium homeostasis, exogenous and endogenous toxins, and mitochondrial dysfunction. An endogenous neurotransmitter dopamine (DA) is thought to be a major source of oxidative stress to these neural cells (Olanow, 1993; Offen et al., 1997). DA contains an unstable catechol moiety, and it can oxidize spontaneously to form ROS, free radicals, and quinones (Cohen and Heikkila, 1974; Graham, 1978; Hastings, 1995). In the human substantia nigra, the DA oxidation products may further polymerize to form another neurotoxin, neuromelanin (Jellinger et al., 1993). These oxidation products can damage cellular components such as lipids, proteins, and DNA (Halliwell, 1992).

One of the plausible ways to prevent the cell death induced by oxidative stress is dietary or pharmacological intake of antioxidants. Lai and $\mathrm{Yu}$ (1997) showed that DA-induced apoptosis is protected by some antioxidants such as glutathione and $\mathrm{N}$-acetyl-L-cysteine. One family of naturally occurring compounds possessing free radical scavenging properties is the polyphenols. It is found in fruit, vegetables and plant-derived beverages and may have important roles as dietary components via cytoprotective actions in many organs (Youdim and Joseph, 2001). Resveratrol (3,5,4'-tihydroxy-trans-stilbene), a 
polyphenolic phytoalexin found in the skin of grapes, has been reported to possess a wide range of biological and pharmacological activities including antioxidant, anti-inflammatory, antimutagenic, and anticarcinogenic effects (Jang et al., 1997; Soleas et al., 1997; Surh, 1999). In previous studies, antioxidant properties of resveratrol attenuated hippocampal cell death and intracellular ROS formation (Bastianetto et al., 2000). Neuroprotective activities against excitotoxic brain damage (Virgili and Contestabile, 2000) and anti-apoptotic effects by caspase activation (Nicolini et al., 2001) suggest a putative neuroprotective action for resveratrol.

In the present study, we have examined the possible protective effect of resveratrol against apoptosis induced by DA in human derived neurotypic cell, SH-SY5Y. Our results indicate that DA indeed triggers apoptosis and this deleterious effect can be attenuated by resveratrol.

\section{Materials and Methods}

\section{Materials}

MEM, FBS and penicillin and streptomycin were obtained from Gibco BRL (Grand Island, NY). Resveratrol, dopamine, DMSO, Hoechst 33254, propidium iodide (PI) were obtained from Sigma (St. Louis, MO). DA and resveratrol were dissolved in sterilized $\mathrm{H}_{2} \mathrm{O}$ and in DMSO, respectively. Annexin $\mathrm{V}$ was from BD Biosciences (Palo Alto, CA). Monoclonal antibodies against caspase-3, Bcl-2, cleavage form of PARP were obtained from Cell Signaling Technology (Danvers, MA). Bicinchoninic acid protein assay kit and ECL chemiluminescence system were obtained from Pierce (Rockford, IL).

\section{Cell culture}

Catecholaminergic neuroblastoma SH-SYSY cells were grown in MEM supplemented with $10 \%$ FBS, $100 \mathrm{U} / \mathrm{ml}$ penicillin, and $100 \mu \mathrm{g} / \mathrm{ml}$ streptomycin. Cells were maintained in a humidified atmosphere of $5 \% \mathrm{CO}_{2}$, at $37^{\circ} \mathrm{C}$. The cells were plated at an appropriate density according to each experimental scale.

\section{Cell viability assay}

Cell viability was determined using Cell Titer $96 \mathrm{Aqu}-$ eous Non-Radioactive Cell Proliferation Assay, available from Promega Corp (Madison, WI). MTS (3-(4,5dimethylthiazol-2-yl)-5-(3-carboxymethoxyphenyl)-2(4-sulfophenyl)-2H-tetrazo-lium inner salt) conversion assay was performed according to the protocol supplied by the manufacturer. In brief, a mixture of MTS and PMS (phenazine methosulfate) was added to the treated SH-SY5Y cells cultured in 96-well plates and incubated in the $\mathrm{CO}_{2}$ incubator for $3 \mathrm{~h}$. Plates were read with a microplate reader at a wavelength of $490 \mathrm{~nm}$. Results were expressed as the percentage of MTS reduction, assuming that the absorbance of control cells was $100 \%$. For each experiment, all treatments were performed in triplicate wells.

\section{Nuclear staining for assessment of apoptosis}

SH-SY5Y cells were stained with the chromatinspecific dye Hoechst 33324 (Molecular Probes, Eugene, OR). The SH-SY5Y cells on the chamber culture slide were incubated for 2 days, and then treated with or without the resveratrol and DA at different concentrations. SH-SY5Y cells were fixed for 10 min with $3.5 \%$ paraformaldehyde in PBS at room temperature. After twice rinses with PBS, the cells were stained with $10 \mu \mathrm{g} / \mathrm{ml}$ Hoechst 33324 in PBS for $10 \mathrm{~min}$ at $37^{\circ} \mathrm{C}$. Mounted slides were analyzed under a fluorescence microscope (Axiovert 135, ZEISS, Germany) using a mercury lamp through a $360-370 \mathrm{~nm}$ bandpass filter. Light emitted from Hoechst dye was collected through a $420 \mathrm{~nm}$ longpass filter.

\section{Measurement of mitochondrial membrane potential} The level of mitochondrial membrane potential (MMP) was determined by flow cytometry and the fluorescent dye rhodamine 123 . The rhodamine 123 data were recorded using an FL-1 photomultiplier. Sample data $(10,000$ cells) were used to prepare histograms of the Cell Quest data analysis program (Becton Dickinson).

Flow cytometric analysis using Annexin V and PI SH-SY5Y cells were centrifuged to remove the medium, washed with PBS and stained with Annexin V-FITC and PI in binding buffer (10 mM Hepes, 140 $\mathrm{mM} \mathrm{NaCl}, 2.5 \mathrm{mM} \mathrm{CaCl}_{2}$ ). Ten thousand events were collected on each sample. Stained cells were analyzed using a FACScalibur (Becton Dickinson, Mountain View, CA) in the FL1-H and FL2-H channels.

\section{Immunoblot analysis}

Blotting was performed essentially as described previously (Schulz et al., 1999). The cells treated with or without resveratrol and DA, were washed once with ice-cold PBS and then lysed using icecold RIPA buffer and protease inhibitor cocktail (Sigma) at $4^{\circ} \mathrm{C}$ for $30 \mathrm{~min}$. Cell lysates were centrifuged at $13,000 \mathrm{rpm}$ for $25 \mathrm{~min}$, and the protein concentrations were determined by the bicinchoninic acid method (Pierce, Rockford, IL) using BSA as 
standard. The protein lysates were separated by $12 \%$ SDS-PAGE and transferred to nitrocellulose membrane (Bio-Rad, CA). Protein expression was detected using primary antibodies and secondary antibodies conjugated with HRP.

\section{Ressults}

\section{Resveratrol protected SH-SY5Y cells against DA-induced cytotoxicity}

DA concentrations from 0 to $500 \mu \mathrm{M}$ were tested and demonstrated that DA is capable of induce metabolic interruption in SH-SY5Y cells in a dose range of $300-500 \mu \mathrm{M}$ (Figure 1A). DA decreased cell viability concentration over time (Figure 1B). Prior studies have shown that resveratrol at up to $10 \mu \mathrm{M}$ slightly promotes cell proliferation, while higher concentration resulted in significant apoptosis (Stervbo et al., 2006). We now found that $5 \mu \mathrm{M}$

A

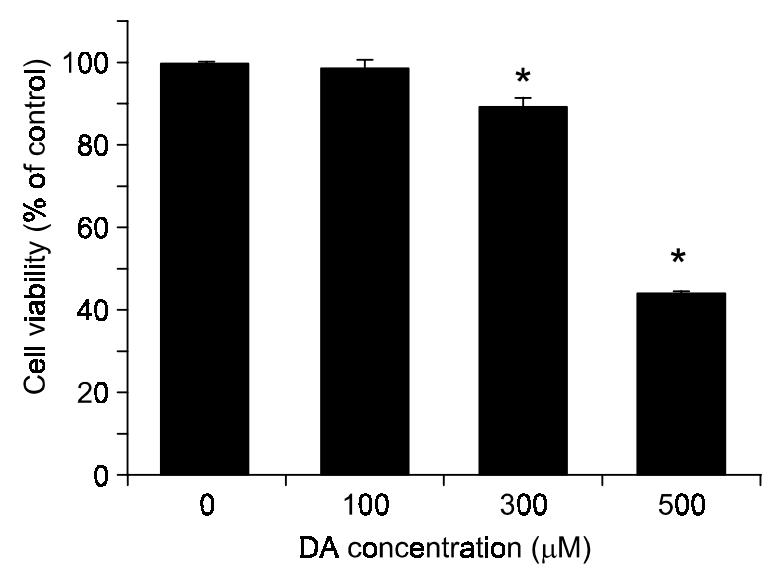

C

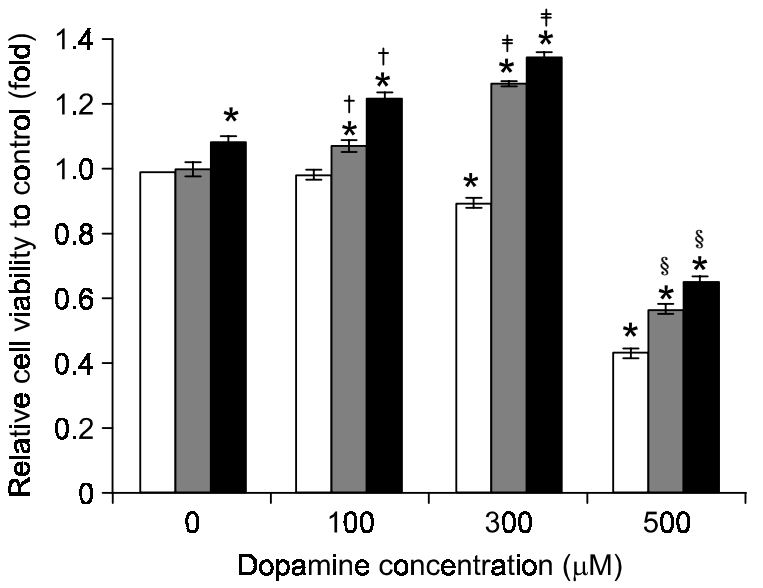

resveratrol slightly but significantly increased cell proliferation and DA-induced apoptotic effects were markedly attenuated by the co-presence of 3 or $5 \mu \mathrm{M}$ resveratrol (Figure 1C).

\section{Resveratrol attenuated DA-induced apoptotic cell death}

SH-SY5Y cells treated for $24 \mathrm{~h}$ with DA at concentrations of 300 and $500 \mu \mathrm{M}$ exhibited morphological alterations such as cell shrinkage and membrane blebbing that are normally associated with the occurrence of apoptotic cell death. Compared to the normal SH-SY5Y cells (Figure 2A), cells treated with DA round up, detached from the bottom, and aggregated as assessed by phase-contrast microscopy (Figure 2B and $\mathrm{D}$ ). Resveratrol pretreatment mitigated these pathologic morphological features (Figure 2C and E). The presence of apoptotic cells was further confirmed by measurement of nuclear

\section{B}

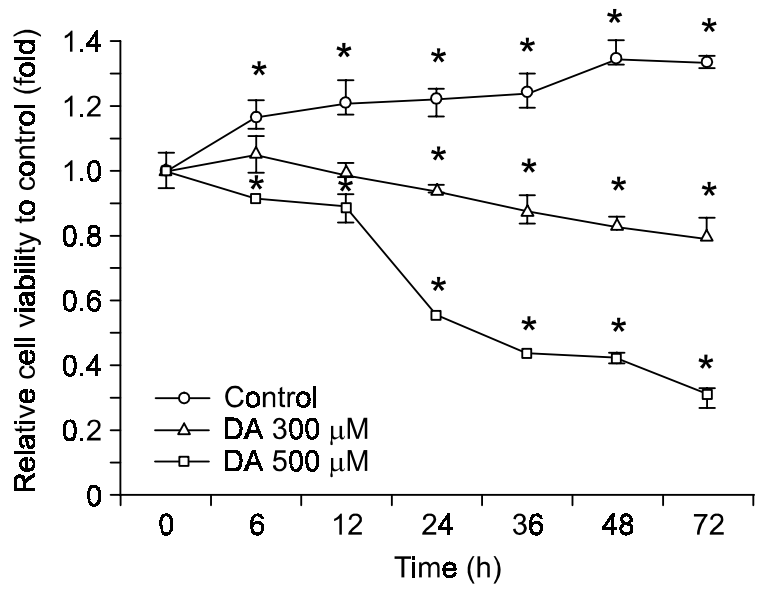

Resveratrol $0 \mu \mathrm{M}$

Resveratrol $3 \mu \mathrm{M}$

Resveratrol $5 \mu \mathrm{M}$

Figure 1. Effect of resveratrol on the DA-induced decrease in SH-SY5Y cells' viability. The number of viable cells was determined by the MTS assay. Resveratrol was added to the media $1 \mathrm{~h}$ prior to the DA treatment. (A) SH-SY5Y cells were treated with different concentrations of DA for $24 \mathrm{~h}$. (B) SH-SY5Y cells were incubated for $0-72 \mathrm{~h}$ with $300 \mu \mathrm{M}$ or $500 \mu \mathrm{M}$ of DA. (C) SH-SY5Y cells were treated with indicated concentrations of DA in the absence or presence of resveratrol for $24 \mathrm{~h}$. For statistical analysis, we conducted a paired t-test. ${ }^{*} P<0.05$ compared with control cells. ${ }^{\dagger} P<0.05,{ }^{7} P<$ $0.005,{ }^{\S} P<0.005$ vs. DA $100 \mu \mathrm{M}$ or $300 \mu \mathrm{M}$ or $500 \mu \mathrm{M}$ treated cells, respectively. 

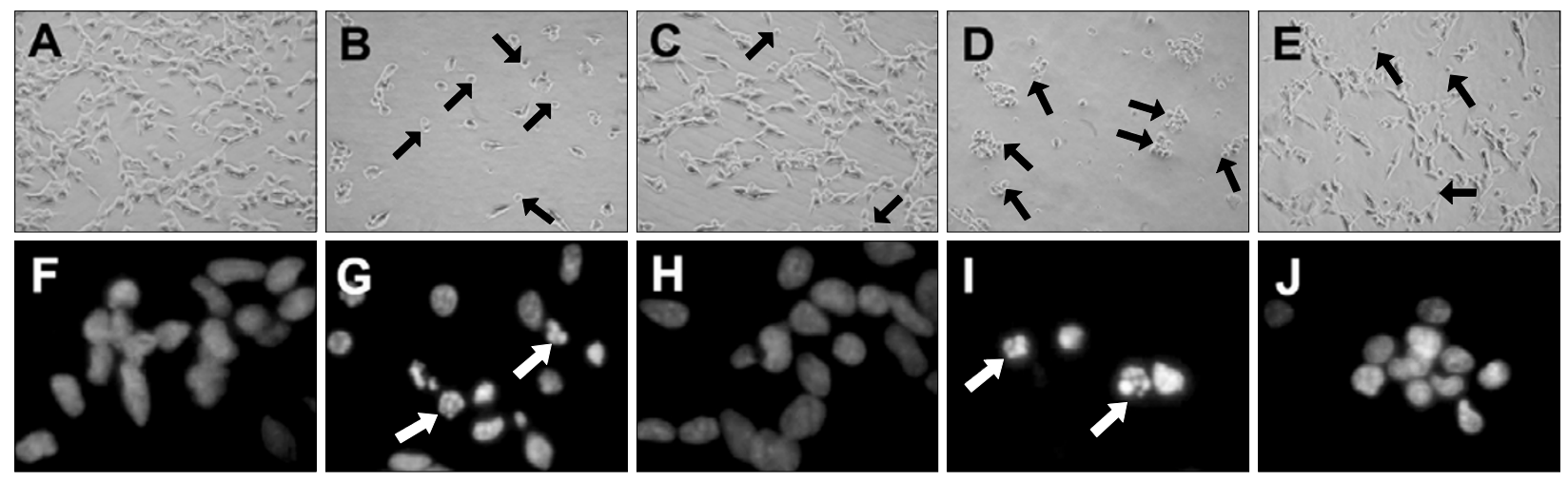

Figure 2. Microscopic analysis of resveratrol on DA-induced cell death. The figures show the phase-contrast photographs of SH-SY5Y cells after DA treatment in the absence or presence of resveratrol. The black arrows indicate typical apoptotic cells with round shape. Nuclear condensation was determined by Hoechst 33342 staining. The white arrows indicate apoptotic cells demonstrating partially condensed nuclei: $(A, F)$ No treatment; (B, G) DA $300 \mu \mathrm{M}$; (C, H) DA $300 \mu \mathrm{M}+$ resveratrol $5 \mu \mathrm{M}$; (D, I) DA $500 \mu \mathrm{M}$; (E, J) DA $500 \mu \mathrm{M}+$ resveratrol $5 \mu \mathrm{M}$.

condensation using Hoechst 33342 (Hanrott et al., 2006). Treatment with 300 and $500 \mu \mathrm{M}$ DA significantly increased the proportion of condensed nuclei (Figure 2G and I). This incidence of cells with nuclear condensation was significantly reduced in DA-treated cells by $5 \mu \mathrm{M}$ resveratrol treatment (Figure $2 \mathrm{H}$ and $\mathrm{J}$ ). In addition, DNA fragmentation analysis was carried out, suggesting that DA-induced apoptosis was significantly reversed by resveratrol (data not shown).

\section{Resveratrol had a protective effect on DA-induced dissipation of the mitochondrial membrane potential}

The $\mathrm{Bcl}-2$ family has a regulatory role in mitochondrial permeability transition pore opening and has an anti-apoptotic property (Crompton, 2000). Upon mitochondrial permeability transition pore opening, mitochondria lose their membrane potential across the inner membrane. Disruption of the MMP has been recognized in DA-induced apoptosis (Tang et al., 2005a). To examine if DA-induced apoptosis and its rescue by resveratrol involve an MMP pathway in SH-SY5Y cells, measurement of MMP was carried out using rhodamine 123 (Tang et al., 2005b). Preconditioning with DA alone induced the rapid depolarization of the MMP. In 300 and $500 \mu \mathrm{M}$ DAconditioned media, the degrees of depolarization were $65.1 \%$ and $74.5 \%$, respectively (Figure $3 \mathrm{~B}$ and D). However, preconditioning with resveratrol at 5 $\mu \mathrm{M}$ had protective effects with $43.5 \%$ and $55.6 \%$ of MMP at 300 and $500 \mu \mathrm{M}$ DA, respectively $(P<$ 0.005 , each when compared to without resveratrol). These results indicate that DA-induced dissipation of the MMP can be effectively blocked by the pretreatment with resveratrol.

\section{DA-induced cell death is attenuated in resveratrol-treated cells}

To quantify cell death induced by DA, we have utilized flow cytometric analysis of externalization of phosphatidyl serine using Annexin V/PI. As shown in Figure 4, cells stained negative for both Annexin $V$ and $\mathrm{PI}\left(\mathrm{PS}^{-} / \mathrm{PI}^{-}\right)$were live cells as shown in the lower left quadrant (R3). Annexin $\mathrm{V}$ positive and PI-negative $\left(\mathrm{PS}^{+} / \mathrm{PI}^{-}\right)$stained cells undergo early stages of apoptosis, where the plasma membrane are still intact and exclude PI (lower right quadrant, R4). In late stages of apoptosis, dying cells can no longer exclude $\mathrm{PI}$ and the upper right region (R2) displayed both Annexin V-positive and PI-positive $\left(\mathrm{PS}^{+} / \mathrm{PI}^{+}\right)$. PI positive and Annexin $V$-negative $\left(\mathrm{PS}^{-} / \mathrm{PI}^{+}\right)$stained cells in the upper left region (R1) were necrotic cells. Our data confirms that DA was capable of inducing cell death in SH-SY5Y cells. The increases of cell death over control in $300 \mu \mathrm{M}$ DA treated cells were $6.6 \%$ in R2, and $24.1 \%$ in R4, respectively. Exposure to $\mathrm{DA}$ resulted in a significant increase in cell death (30.7\%, $P<0.01$ vs control) in SH-SY5Y cells. Similarly, $500 \mu \mathrm{M}$ DA-treated cells also exhibited a marked increase in cell death $(54.1 \%, P<0.01$ vs control). In contrast, resveratrol-pretreated SH-SY5Y cells showed significant resistance to DA-induced cytotoxicity because approximate $19.4 \%$ and $31.4 \%$ of the cells were affected, respectively (Figure 4, $P$ 0.01 vs. DA-only treated cells).

\section{Resveratrol influenced the DA-induced apoptotic signaling pathway}

To gain further insight into the way in which resveratrol is neuroprotective, we studied its effect on the possible caspases activated during the process of 
A

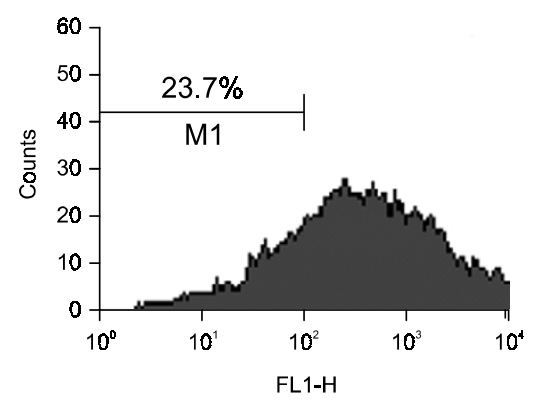

C

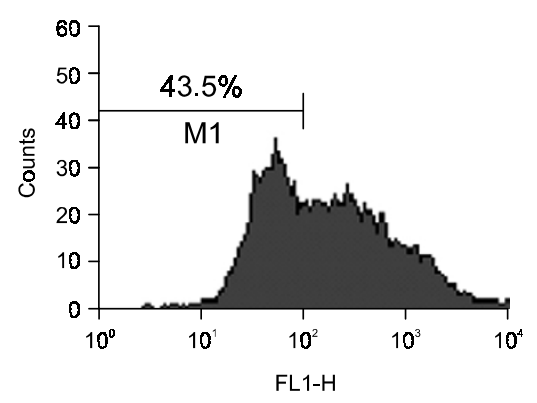

E

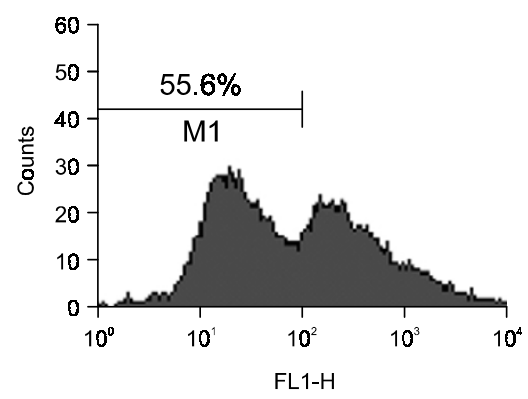

B

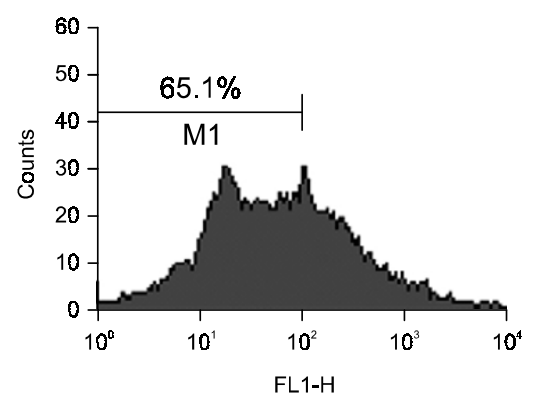

D
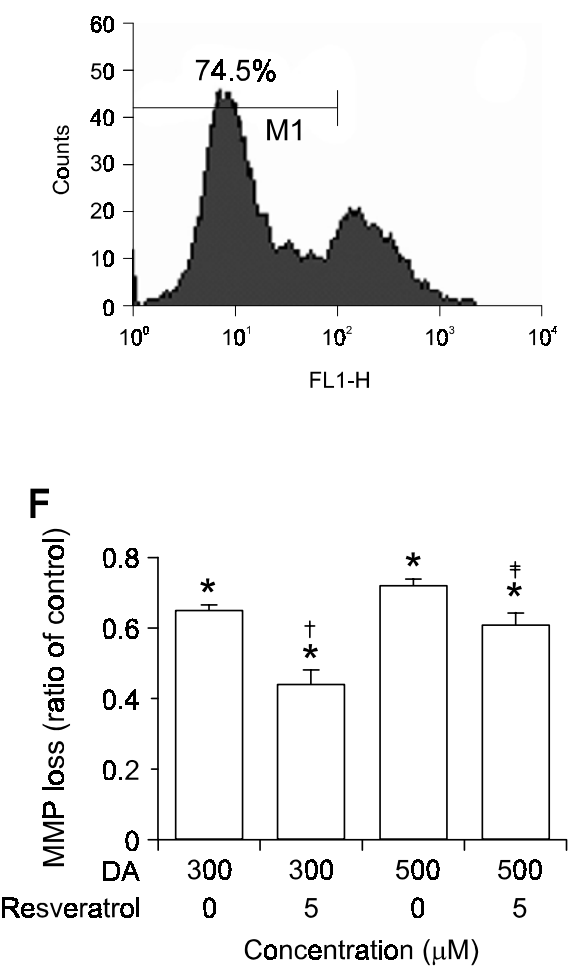

Figure 3. Effect of resveratrol preconditioning on DA-induced dissipation of mitochondrial membrane potential. MMP alteration was measured by flow cytometry using rhodamine 123 staining. The number in $M 1$ indicates the percentage of cells with a reduced MMP level. SH-SY5Y cells were incubated in drug-free medium $(A)$ or medium containing $300 \mu \mathrm{M}$ or 500 $\mu \mathrm{M} D A(B, D)$; or cells were preincubated with $5 \mu \mathrm{M}$ resveratrol and then exposed to DA for $24 \mathrm{~h}$ (C, E). (F) A bar graph summary of the averages of rhodamine $123 \mathrm{da}$ ta collected from three independent flow cytometry experiments is shown. Bars represent the standard error of the mean. For statistical analysis, we conducted a Student paired $t$-test. ${ }^{*} P<0.001$ compared with control cells. ${ }^{\dagger} P<$ $0.005,{ }^{\ddagger} P<0.005$ vs. DA $300 \mu \mathrm{M}$ or $500 \mu \mathrm{M}$ treated cells. apoptosis. Caspase- 3 is activated by multiple proteolytic cleavage of its $32 \mathrm{kDa}$ precursor form to generate an enzymatically active p12/p17 complex, which has been used to monitor the activation of caspase-3 (Nicholson et al., 1995). Treatment of SHSY5Y cells with 300 and $500 \mu \mathrm{M}$ DA induced the cleavage of caspase-3, demonstrated by the appearance of $\mathrm{p} 17$ fragments detected by an antibody for the cleaved form of caspase- 3 and full-length caspase-3 (Figure 5). The increase in caspase-3 cleavage was associated with increased poly ADPribose polymerase (PARP) cleavage, a down stream substrate of caspase-3, and the extent of DAinduced PARP cleavage was also rescued by res- veratrol (Figure 5).

We also examined the expression of $\mathrm{Bcl}-2$ protein. Treatment of SH-SY5Y cells with DA decreased the expression of $\mathrm{Bcl}-2$, which was reversed by resveratrol pretreatment (Figure 5). The partial restoration of $\mathrm{Bcl}-2$ by resveratrol implies the possible involvement of other antiapoptotic proteins in regulating the death and survival in SH-SY5Y cells. These results suggested that resveratrol treatment shifted the balance between positive and negative regulators of apoptosis towards cell survival through canonical apoptosis signaling pathways. 
A

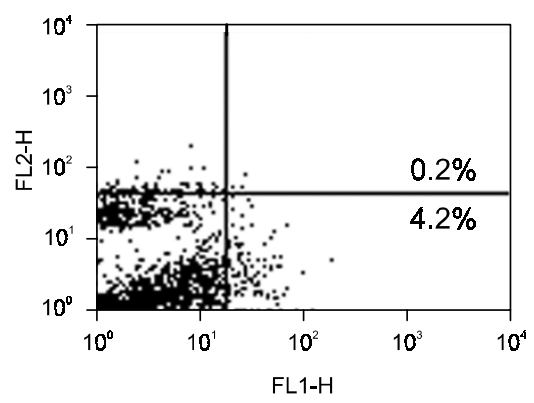

C

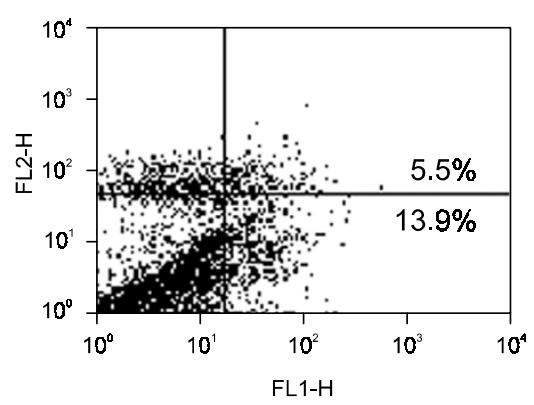

E

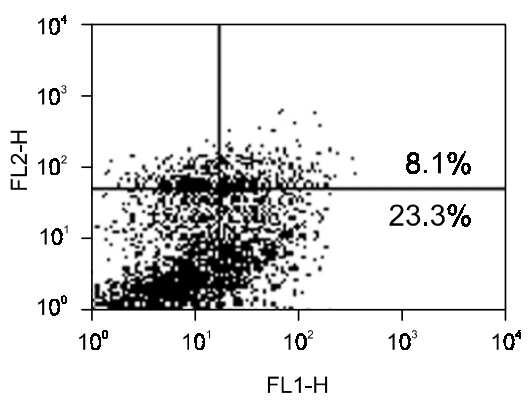

B

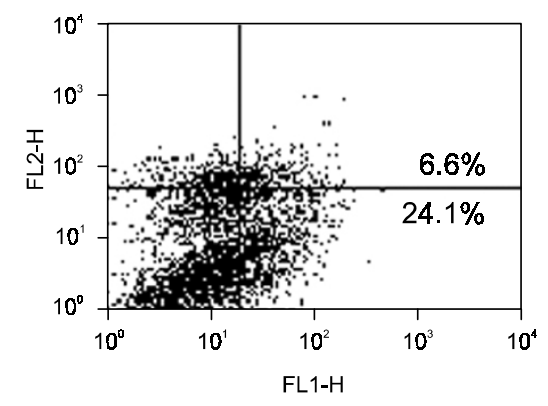

D

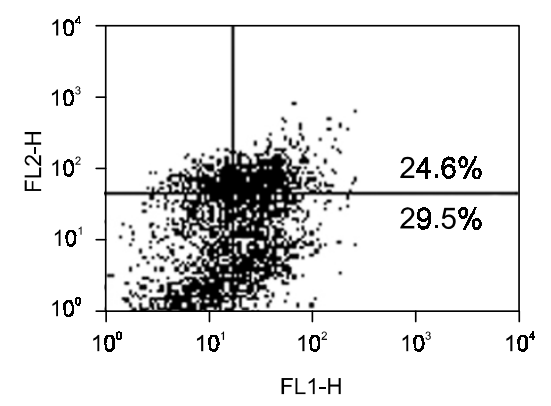

F

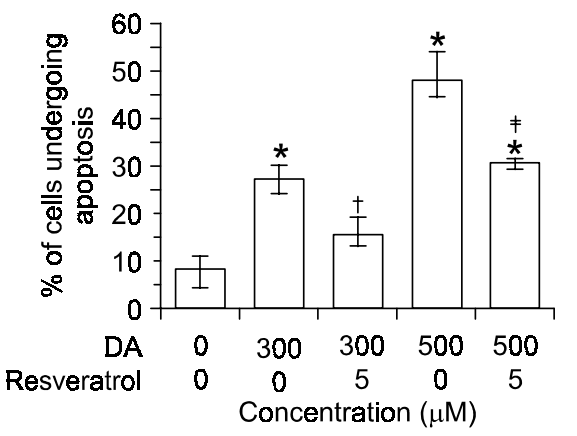

Figure 4. Effect of resveratrol on DA-induced apoptosis in SH-SY5Y cells measured by flow cytometry. Flow cytometric analysis of $\mathrm{SH}$ SY5Y cells stained with Annexin V and PI performed $24 \mathrm{~h}$ after cells were exposed to the experimental condition. The number in the lower right quadrant denotes the percentage of early apoptotic cells, and the number in the upper right quadrant denotes the percentage of late apoptotic cells. The results shown in $(F)$ are the standard error of the mean for three independent experiments. (A): no treatment; (B): 300 $\mu \mathrm{M} \mathrm{DA}$; (C): $300 \mu \mathrm{M} \mathrm{DA}+5 \mu \mathrm{M}$ resveratrol; (D): $500 \mu \mathrm{M} \mathrm{DA}$; and (E): $500 \mu \mathrm{M} \mathrm{DA}+5 \mu \mathrm{M}$ resveratrol. For statistical analysis, we conducted a Student paired $t$-test. ${ }^{*} P$ $<0.01$ compared with control cells. ${ }^{\dagger} P<0.001,{ }^{\ddagger} P<0.01$ vs. DA $300 \mu \mathrm{M}$ or $500 \mu \mathrm{M}$ treated cells.

\section{Discussion}

Previous studies indicate that DA, although it is an essential neurotransmitter under physiological conditions, may participate in neurodegenerative processes as a neurotoxin (Luo et al., 1998). Oxidative stress has been proposed as a major source of dopaminergic neuronal degeneration in PD, and one of the possible causes for oxidative stress is ROS generated during normal DA metabolism (Junn and Mouradian, 2001). The oxidative products of DA may function as stimuli to activate caspases and subsequent apoptosis, similar to other environmental stresses including UV radiation, ionizing radiation and heat shock (Verheij et al., 1996). In contrast, polyphenols possesses free radical scavenging properties and thus, they may have cytoprotective actions in several organs such as kidney and brain (Skrzydlewska et al., 2005; Jang et al., 2006). Resveratrol is a known polyphenolic compound naturally present in grapes, wine, and peanuts (Ulrich et al., 2005), and it has shown to exert antioxidant, anti-inflammatory, antimutagenic, and anticarcinogenic effects (Jang et al., 1997; Soleas et al., 1997; Surh, 1999).

Our data showed that DA significantly induces the cell death in time and dose dependent manner (Figure $1 \mathrm{~A}$ and $\mathrm{B}$ ) and DA-induced cytotoxicity was 


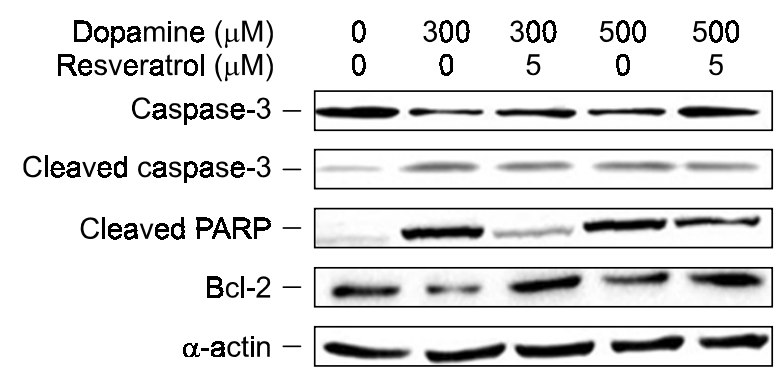

Figure 5. Effect of resveratrol on the DA-induced apoptotic signaling. SH-SY5Y cells were incubated with $300 \mu \mathrm{M}$ or $500 \mu \mathrm{M}$ DA for $24 \mathrm{~h}$ in the presence or absence of $5 \mu \mathrm{M}$ resveratrol and harvested for Immunoblot analysis. The protein of Bcl-2, caspase-3, cleaved form of caspase-3 and PARP were determined using immunoblot analysis with corresponding antibodies. Actin was used as an internal control. Each blot is representative of three independent experiments.

partially restored by 3-5 $\mu \mathrm{M}$ resveratrol (Figure $1 \mathrm{C}$ ). The cytoprotective effects of resveratol appeared to be better by low concentration resveratrol than by high concentration resveratrol of $10-25 \mu \mathrm{M}$ (data not shown). In previous study, resveratrol was actually shown to have dual functions at different concentrations: High concentrations of resveratrol (40-160 $\mu \mathrm{M})$ induce apoptosis, whereas cell proliferation increased at low concentrations of resveratrol (up to $10 \mu \mathrm{M})$ (Stervbo et al., 2006).

In the present study, DA caused apoptotic cell death with significant morphological nuclear changes (Figure 2), consistent with previous in vitro studies (Emdadul Haque et al., 2003). To examine the role of DA for SH-SY5Y cell apoptosis, change of MMP was traced in the experimental conditions. Maintenance of MMP is necessary for production of energy (ATP) and preservation of cellular homeostasis, and is a critical primary determinant of cell survival (Akao et al., 2003). We confirm that DA causes dissipation of MMP and that inhibition of MTS conversion and disruptions in mitochondrial functions may be involved in the mechanisms of DA-induced apoptosis in SH-SY5Y cells. We now show that this effect is inhibited by pretreatment with resveratrol (Figure 3), and that the protective effect of resveratrol against DA-induced apoptosis might be related to the production of ATP and the preservation of cellular homeostasis.

A key event during the early stage of apoptosis is that PS of the inner leaflet of the cell membrane appears on the outer leaflet. Annexin V preferentially binds to PS and can be used to detect expression of PS on the surface of apoptotic cells. PI diffuses into necrotic cells (Nicolini et al., 2001), and was used in these experiments as an indicator of lost of cell membrane integrity. Membrane permeability by dual staining with Annexin $\mathrm{V}$ and $\mathrm{PI}$ revealed that high concentrations of DA (300 and $500 \mu \mathrm{M})$ significantly damaged plasma membrane integrity. These deleterious effects on SH-SY5Y cells can be reversed by resveratrol (Figure 4).

The decrease in MMP is a necessary step for inducing cytochrome $c$ release and caspase- 3 activation in many apoptotic events (Perkins et al., 2000; Qiu et al., 2000). Caspases play an important role in the apoptotic process by two distinct pathways: the death receptor pathway and the mitochondrial pathway (Markus, 2000). Whichever pathway is involved, caspase-3 acts as an apoptotic executor. Caspase-3 activates DNA fragmentation factor, which in turn activated endonucleases to cleave nuclear DNA, and ultimately leads to cell death (Wang and Xu, 2005). In this study, treatment with DA led to an increase in caspase-3 activity, but resveratrol pretreatment effectively suppressed the caspase- 3 activation. Therefore, resveratrol may act upstream of caspase-3 to block apoptosis.

By virtue of measuring the proteolytic cleavage of nuclear enzyme PARP that is the down-stream target of caspase-3, apoptosis signaling event between DA and resveratrol was tested. Proteolytic cleavage of PARP has been shown to occur during 2,2',5, 5 '-tetrachlorobiphenyl-induced apoptosis in human neuronal SK-N-MC cells (Hwang et al., 2001), and staurosporine-induced apoptosis in dopaminergic neurons (Kim et al., 1999). On activating caspase-3, DA treatment induced the cleavage of PARP. The activation of caspase- 3 as well as the cleavage of PARP that follow DA treatment was also prevented completely by the co-incubation with resveratrol (Figure 5).

$\mathrm{Bcl}-2$ is a key member of the anti-apoptotic $\mathrm{Bcl}-2$ family that plays a key role in regulating mitochondrial-mediated apoptotic cell death (Marchetti et al., 1996; Yang et al., 1997; Tsujimoto, 1998). Bcl-2 has been shown to attenuate caspase- 3 activation ( $\mathrm{Sa}$ wada et al., 2000; Yamakawa et al., 2000), and overexpression of $\mathrm{Bcl}-2$ can protect neuronal cells from neurotoxic insult (Borg and London, 2002; Howard et al., 2002; Saito et al., 2003). In this study, the Bcl-2 protein decreased in the SH-SY5Y cells treated with $D A$, whereas it increased in cells pretreated with resveratrol. These results suggest that DA induces apoptosis through canonical apoptosis signal, and it is possible for resveratrol to suppress apoptotic cell death signals induced by DA.

In summary, DA caused apoptosis in SH-SY5Y cells through the induction of oxidative stress pathways, and this apoptotic effect can be ameliorated by resveratrol pretreatment in a specific, low dose range. The elucidation of intracellular signal in response to DA-induced oxidative stress and their mo- 
dulation by resveratrol may provide additional insights into the molecular basis of the neuroprotective effects of this antioxidant phytochemical. Whether DA contributes significantly to the development of $P D$, needs further studies as does whether resveratol or related polyphenolic compounds may have a role in prevention of the advancement of PD, remains to be determined.

\section{References}

Akao M, O'Rourke B, Teshima Y, Seharaseyon J, Marba'n E. Mechanistically distinct steps in the mitochondrial death pathway triggered by oxidative stress in cardiac myocytes. Circ Res 2003;92:186-94

Bastianetto S, Zheng WH, Quirion R. Neuroprotective abilities of resveratrol and other red wine constituents against nitric oxide-related toxicity in cultured hippocampal neurons. $\mathrm{Br} \mathrm{J}$ Pharmacol 2000;131:711-20

Borg J, London J. Copper/zinc superoxide dismutase overexpression promotes survival of cortical neurons exposed to neurotoxins in vitro. J Neurosci Res 2002;70:180-9

Cohen G, Heikkila RE. The generation of hydrogen peroxide, superoxide radical, and hydroxyl radical by 6 -hydroxydopamine, dialuric acid, and related cytotoxic agents. J Biol Chem 1974;249:2447-52

Crompton M. Bax, Bid and the permeabilization of the mitochondrial outer membrane in apoptosis. Curr Opin Cell Biol 2000;12:414-9

Emdadul Haque M, Asanuma M, Higashi Y, Migazaki I, Tanaka $\mathrm{K}$, Ogawa N. Apoptosis-inducing neurotoxicity of dopamine and its metabolites via reactive quinone generation in neuroblastoma cells. Biochim Biophys Acta 2003;1619:39-52

Graham DG. Oxidative pathways for catecholamines in the genesis of neuromelanin and cytotoxic quinones. Mol Pharmacol 1978;14:633-43

Halliwell B. Reactive oxygen species and the central nervous system. J Neurochem 1992;59:1609-23

Hanrott K, Gudmunsen L, O'Neill MJ, Wonnacott S. 6-hydroxydopamine-induced apoptosis is mediated via extracellular auto-oxidation and caspase 3-dependent activation of protein kinase Cdelta. J Biol Chem 2006;281:5373-82

Hastings TG. Enzymatic oxidation of dopamine: the role of prostaglandin H synthase. J Neurochem 1995;64:919-24

Howard S, Bottino C, Brooke S, Cheng E, Giffard RG, Sapolsky R. Neuroprotective effects of bcl-2 overexpression in hippocampal cultures: interactions with pathways of oxidative damage. J Neurochem 2002;83:914-23

Hwang SG, Lee HC, Lee DW, Kim YS, Joo WH, Cho YK, Moon JY. Induction of apoptotic cell death by a p53-independent pathway in neuronal SK-N-MC cells after treatment with 2,20,5,50-tetrachlorobiphenyl. Toxicology 2001;165:179-88

Jang M, Cai L, Udeani GO, Slowing KV, Thomas CF, Beecher CW, Fong HH, Farnsworth NR, Kinghorn AD, Mehta RG, Moon
RC, Pezzuto JM. Cancer chemopreventive activity of resveratrol, a natural product derived from grapes. Science $1997 ; 275: 218-20$

Jang YH, Lee YC, Park NH, Shin HY, Mun KC, Choi MS, Lee MY, Kim AR, Kim JM, Lee SR, Park HR. Polyphenol (-)-epigallocatechin gallate protection from ischemia/reperfusion-induced renal injury in normotensive and hypertensive rats. Transplant Proc 2006;38:2190-4

Jellinger K, Kienzl E, Rumpelmair G, Riederer P, Stachelberger H, Ben-Shachar D, Youdim MB. Neuromelanin and nigrostriatal dopamine neuron degeneration. J Neurochem 1993; 59:1168-71

Jiang H, Zhang L, Kuo J, Kuo K, Gautam SC, Groc L, Rodriguez Al, Koubi D, Hunter TJ, Corcoran GB, Seidman MD, Levine RA. Resveratrol-induced apoptotic death in human U251 glioma cells. Mol Cancer Ther 2005;4:554-61

Junn E, Mouradian MM. Apoptotic signaling in dopamine-induced cell death: the role of oxidative stress, p38 mitogen-activated protein kinase, cytochrome $c$ and caspases. J Neurochem 2001;78:374-83

Kim JE, Oh JH, Choi WS, Chang II, Sohn S, Krajewski S, Reed JC, O'Malley KL, Oh YJ. Sequential cleavage of poly(ADP-ribose)polymerase and appearance of a small Bax-immunoreactive protein are blocked by $\mathrm{Bcl}-\mathrm{X}(\mathrm{L})$ and caspase inhibitors during staurosporine induced dopaminergic neuronal apoptosis. J Neurochem 1999;72:2456-63

Lai CT, Yu PH. Dopamine- and L-beta-3,4-dihydroxyphenylalamine hydrochloride (L-Dopa)-induced cytotoxicity towards catecholaminergic neuroblastoma SH-SY5Y cells. Effects of oxidative stress and antioxidative factors. Biochem Pharmacol 1997;53:363-72

Luo Y, Umegaki H, Wang X, Abe R, Roth GS. Dopamine induces apoptosis through an oxidation-involved SAPK/JNK activation pathway. J Biol Chem 1998;273:3756-64

Marchetti P, Hirsch T, Zamzami N, Castedo M, Decaudin D, Susin SA, Masse B, Kroemer G. Mitochondrial permeability transition triggers lymphocyte apoptosis. J Immunol 1996; 157:4830-6

Markus GG. Caspases: key players in programmed cell death. Curr Opin Struct Biol 2000;10:649-55

Mohan J, Gandhi AA, Bhavya BC, Rashmi R, Karunagaran D, Indu R, Santhoshkumar TR. Caspase-2 triggers Bax-Bak-dependent and -independent cell death in colon cancer cells treated with resveratrol. J Biol Chem 2006;281:17599-611

Nicholson DW, Ali A, Thornberry NA, Vaillancourt JP, Ding CK, Gallant M, Gareau Y, Griffin PR, Labelle M, Lazebnik YA, Munday NA, Raju SM, Smulson ME, Yamin T-T, Yu VL, Miller DK. Identification and inhibition of the ICE/CED-3 protease necessary for mammalian apoptosis. Nature 1995;376:37-43

Nicolini G, Rigolio R, Miloso M, Bertelli AAE, Tredici G. Anti-apoptotic effect of trans-resveratrol on paclitaxel-induced apoptosis in the human neuroblastoma SH-SY5Y cell line. Neurosci Lett 2001;302:41-4

Offen D, Ziv I, Panet H, Wasserman L, Stein R, Melamed E, Barzilai A. Dopamine-induced apoptosis is inhibited in PC12 cells expressing Bcl-2. Cell Mol Neurobiol 1997;17:289-304 
Olanow $\mathrm{CW}$. A rationale for monoamine oxidase inhibition as neuroprotective therapy for Parkinson's disease. Mov Disord 1993;8 Suppl 1:S1-7

Perkins CL, Fang G, Kim CN, Bhalla KN. The role of Apaf-1, caspase-9, and bid proteins in etoposide- or paclitaxel-induced mitochondrial events during apoptosis. Cancer Res 2000;60:1645-53

Qiu JH, Asai A, Chi S, Saito N, Hamada H, Kirino T. Proteasome inhibitors induce cytochrome c-caspase-3-like proteasemediated apoptosis in cultured cortical neurons. J Neurosci 2000;20:259-65

Saito A, Hayashi T, Okuno S, Ferrand-Drake M, Chan PH. Overexpression of copper/zinc superoxide dismutase in transgenic mice protects against neuronal cell death after transient focal ischemia by blocking activation of the Bad cell death signaling pathway. J Neurosci 2003;23:1710-8

Sawada M, Nakashima S, Banno Y, Yamakawa H, Takenaka K, Shinoda J, Nishimura Y, Sakai N, Nozawa Y. Influence of Bax or Bcl-2 overexpression on the ceramide-dependent apoptotic pathway in glioma cells. Oncogene 2000;19:3508-20

Schulz JB, Weller M, Moskowitz MA. Caspases as treatment targets in stroke and neurodegenerative diseases. Ann Neurol 1999;45:421-9

Skrzydlewska E, Augustyniak A, Michalak K, Farbiszewski R. Green tea supplementation in rats of different ages mitigates ethanol-induced changes in brain antioxidant abilities. Alcohol 2005;37:89-98

Soleas GJ, Diamandis EP, Goldberg DM. Resveratrol: a molecule whose time has come? And gone? Clin Biochem 1997; 30:91-113

Stervbo U, Vang O, Bonnesen C. Time- and concentration- dependent effects of Resveratrol in HL-60 and HepG2 cells. Cell Prolif 2006;39:479-93

Surh YJ. Molecular mechanisms of chemopreventive effects of selected dietary and medicinal phenolic substances. Mutat Res 1999;428:305-27

Tang XQ, Zhi JL, Cui YU, Feng JQ, Chen PX. Hydrogen peroxide preconditioning protects PC12 cells against apoptosis induced by dopamine. Life Sci 2005a;78:61-6
Tang XQ, Feng JQ, Chen J, Chen PX, Zhi JL, Cui Y, Guo RX Yu HM. Protection of oxidative preconditioning against apoptosis induced by $\mathrm{H} 2 \mathrm{O} 2$ in PC 12 cells: mechanisms via MMP, ROS, and Bcl-2. Brain Res 2005b;1057:57-64

Tewari M, Quan LT, O'Rourke K, Desnoyers S, Zeng Z, Beidler DR, Poirier GG, Salvesen GS, Dixit VM. Yama/CPP32 beta, a mammalian homolog of CED-3, is a CrmA-inhibitable protease that cleaves the death substrate poly (ADP-ribose) polymerase. Cell 1995;81:801-9

Tsujimoto Y. Role of Bcl-2 family proteins in apoptosis: apoptosomes or mitochondria? Genes Cells 1998;3:697-707

Ulrich S, Wolter F, Stein JM. Molecular mechanisms of the chemopreventive effects of resveratrol and its analogs in carcinogenesis. Mol Nutr Food Res 2005;49:452-61

Verheij M, Bose R, Lin XH, Yao B, Jarvis WD, Grant S, Birrer MJ, Szabo E, Zon LI, Kyriakis JM, Haimovitz-Friedman A, Fuks Z, Kolesnick RN. Requirement for ceramide-initiated SAPK/ JNK signalling in stress-induced apoptosis. Nature 1996; 380:75-9

Virgili M, Contestabile A. Partial neuroprotection of in vivo excitotoxic brain damage by chronic administration of the red wine antioxidant agent, trans-resveratrol in rats. Neurosci Lett 2000;281:123-6

Wang XJ, Xu JX. Salvianic acid A protects human neuroblastoma $\mathrm{SH}-\mathrm{SY} 5 \mathrm{Y}$ cells against MPP ${ }^{+}$-induced cytotoxicity. Neurosci Res 2005;51:129-38

Yamakawa H, Ito Y, Naganawa T, Banno Y, Nakashima S, Yoshimura S, Sawada M, Nishimura Y, Nozawa Y, Sakai N. Activation of caspase-9 and -3 during $\mathrm{H}_{2} \mathrm{O}_{2}$-induced apoptosis of PC12 cells independent of ceramide formation. Neurol Res 2000;22:556-64

Yang J, Liu X, Bhalla K, Kim CN, Ibrado AM, Cai J, Peng TI, Jones DP, Wang X. Prevention of apoptosis by Bcl-2: release of cytochrome c from mitochondria blocked. Science 1997; 275:1129-32

Youdim K, Joseph J. A possible emerging role of phytochemicals in improving age-related neurological dysfunctions: a multiplicity of effects. Free Radic Biol Med 2001;30:583-94 